\title{
NETWORKING SOUTH EAST EUROPE IN MANAGING NON-TRADITIONAL CHALLENGES
}

\section{Petya DIMITROVA}

$\mathrm{S}$ outh Eastern Europe's delicate security environment has been a challenge itself for over a decade now. However, the need to foster positive trends region wide and build communities of interest in managing problems together and not against one another has been quite prominent. Typical regional scepticism has started giving way to a more practical approach that builds on positive experiences and inclusive postures. This paper is an attempt to demonstrate how the willingness of South East European states to evolve their vision and attitudes is translated into doable ventures that try to answer the abundance of expectations and make prosperity and progress permanent features of the region.

There are various tools for addressing cooperatively current and prospective security challenges. They range from common security and risk assessment based on identical, or at least aligning, values, perceptions and considerations; common approaches delivered through respective networking and, if and when possible, a joint action.

This holds true for the region of South Eastern Europe as well. The recent redefinition of missions, re-estimation of values, reconsidering of visions, and revision of strategies has been related to certain changes in attitudes and behaviour. In addition, the external changes and internal transition have affected the way problems have been approached and treated. As a result, in the last decade or so the countries in South Eastern Europe have come up with various kinds of documents that present their assessment of the strategic environment and their respective security needs, missions and tasks - be it a national security/defence concept, strategy or something else. They offer new approaches to old problems or treat new problems in a different fashion, and outline the principles of managing capacities and managing activities.

Lately national perspectives as to key security issues have been laid out on a new setting. The political will of the states in the region to consider security challenges 
and address common national concerns together has been vested in a number of initiatives promoting openness and transparency, as well as joint decision-making and practical cooperation.

Some of those initiatives have been inspired and "nursed" by outside actors international organisations or single states, others have been launched within the region, but it is up to the will of South East European countries that implementation is put forward and progress achieved. It is also well understood by the international community. In a resolution adopted 20 December 2000 by the United Nations General Assembly, inter alia, it is confirmed that there is an urgency of consolidating South Eastern Europe as a region of peace, security, stability, democracy, cooperation and economic development and of strengthening relations among the states in the region. The resolution stresses the importance of regional efforts aimed at preventing conflicts, arms control, disarmament and confidence-building measures, as well as closer cooperation in crime prevention, combating illicit trade of people, drug trafficking and money laundering and closer engagement of the South East European states in furthering cooperation on the European continent that will favourably influence the security, political and economic situation in the region. ${ }^{1}$

This corresponds to South East European states' assumptions and understanding too. The region well makes geostrategy, geopolitics and geo-economics matter with various dimensions and emphases. Thus the particular attention paid to security cooperation in South Eastern Europe that is also demonstrated by the Organisation for Security and Cooperation in Europe (OSCE), the European Union (EU), NATO and their member states, can be attributed to the specific regional environment, its challenges and risks as well as to special interests that meet here.

South Eastern Europe is also a region where history matters. And yet, it is more and more the present and the future that have been on the agenda lately. The forward looking approach has been an incentive of an unprecedented sharing and discussing of security concerns. As a result, a headlong dynamics in relations and a considerable abundance in attempts have generated a sometimes still embryonic but rather comprehensive security network in meeting contemporary challenges. The progress therein will be very much subject to the willingness of the states to pursue what has been agreed upon on the strategic (political) level and to implement it effectively in practice. Thus it is very important for South East European states to come to terms by defining their mission and vision clearly, by holding to the same values and developing a common strategy since in most cases a single state's efforts are insufficient and inadequate to the challenges.

It is widely understood that the existence of a certain information environment is the initial crucial step in any attempt for a joint management. It is related to the overall 
openness and transparency that is gradually becoming a feature of security interaction. In the case of South Eastern Europe the actual networking starts on the political level where the security environment and its implications on states is assessed by means of the South East Europe Common Assessment Paper on Regional Security Challenges and Opportunities (SEECAP) - a project within NATO's South East European Initiative (SEEI). There are also other attempts for a joint consideration of security challenges but not as comprehensive in scope and involvement and not really variant in conclusions. For the purpose of this endeavour, it will be the SEECAP that will be inspected in details.

Having a common security assessment it is rather easy to understand and channel the measures taken to address common regional challenges - be it an international formation such as the South East European Brigade (SEEBRIG) and the Operational Group for Naval Cooperation in the Black Sea area (BLACKSEAFOR) for instance, be it a council/group as is the case with the Civil-Military Emergency Planning (CMEP) one, or be it another form of affiliation.

\section{The Assessment}

The South East Europe Common Assessment Paper on Regional Security Challenges and Opportunities (SEECAP) is a real shift from traditional risk and threat assessment. The very aim of the Paper ${ }^{2}$ can be summarised as a contribution to regional cooperation processes vested in various instruments; to dialogue and goodneighbourly relations, promoting better understanding of challenges and facilitating actions to address these challenges. It is a document that sets out perceptions, expectations and agendas shared by South East European countries in their effort to establish practical contacts among national security related bodies and take concerted action.

Since it is still transformation that characterises the strategic environment in South Eastern Europe and diversity that particularises the states in the region, the common resolve to promote peace, security and prosperity in a comprehensive manner is an achievement in itself. However, South East European countries have come to the conclusion that it is necessary to go further than words and take coordinated and even joint action. This effective joint ness of action is viewed as a key element promoting peace, security and stability in the region.

The resolve to respond together is declared and duly pursued though it is widely understood that South East European countries are unequally susceptible to the particular challenges. The SEECAP recognises no direct threat of military aggression between states of South Eastern Europe and it streamlines basic challenges into several categories: political, defence-military, economic, social and environmental. It 
iterates the need to fight real problems such as political and ethnic tensions, organised crime, economic and social failure, civil emergencies, etc., as well as psychological stereotypes and prejudice such as the international perception of the region as a source of insecurity and instability for example. The SEECAP puts a special emphasis on issues like terrorism, weapons and proliferation, early warning, conflict prevention and crisis management capabilities, considering them from both a political and military perspective. It reaffirms the fundamental roles of armed forces as "deterrence, protection, participation in collective and other security arrangements and contribution to international military operations" and stresses the importance of a proper management of change by a respective military and security strategies and doctrines' adaptation as well as a well-reasoned psychological and technical adaptation of military personnel adequate to the new requirements and needs. It also refers to the democratic development challenges as well as the insufficient national and regional mechanisms in meeting problems such as refugee flows, natural disasters, industrial accidents and pollution.

Some of these challenges are met by reinforcing national political and socialeconomic systems; others can only be successfully addressed by a joint effort. The SEECAP welcomes the principle of multinationality in shaping regional response capabilities and mechanisms and is considered to be an initial step on the way to prospective security strategies and planning based on common perceptions. It sets out priorities and venues, making way for complementarity and added value. Its provisions and recommendations support the European and Euro Atlantic course followed by South East European states and fit within the broader security framework provided by the OSCE and the UN. ${ }^{3}$

The SEECAP is a steady consolidating effort and an ever-learning process. It reflects the regional risk environment and offers a multi-faceted security perspective that confirms the most immediate items on the regional agenda: international organised crime and terrorism, drug and arms trafficking and proliferation, economy-related challenges, ecological issues, corruption, information infrastructure threats, natural disasters and industrial accidents, etc. The options for dealing with them therefore range from informing others what is being done on a national scale in conformity with the principles of openness and transparency, to coordinating national efforts, joint decision-making and synchronised implementation by national bodies and employment of joint formations. They present various levels of commitment that reflect the evolution of relations among international actors.

The SEECAP's concept is also vested in a number of initiatives, stemming there from, such as: 
- the comparative study of national security strategies in South East Europe (SEESTUDY);

- the project on the exchange of political-military and other early warning, conflict prevention and crisis management information (SEECHANGE), that envisages the voluntary exchange of classified and non-classified information on the strategic environment, political, defence-military, economic, social and democratic development challenges, as well as environmental challenges and civil emergencies;

- the exchanges of border security personnel (SEESTAFF);

- the promotion of civil-military interaction in security management (SEEMAG);

- the Compendium of Anti-Terrorism Measures in South East Europe.

\section{The Response}

The political will and effort embodied by the SEECAP and other similar endeavours have been translated into various mechanisms and tools for sharing responsibilities and enjoying benefits. Whether it is NATO's SEEI, the South Eastern Europe Cooperation Process (SECP), the Stability Pact or something else, there is always the need for a synergy and coherence among different efforts. They run parallel to the efforts undertaken by South East European states in their capacity as members of the UN, the OSCE, the Council of Europe or derive from various arrangements related to their aspiration or membership in the EU, NATO and other international organisations.

\section{The Mechanisms}

Correspondingly, it is two processes, the Southeast European Defence Ministerial and the Stability Pact for South Eastern Europe, that mostly focus the attention.

It is envisaged, within the political framework of the Southeast European Defence Ministerial (SEDM) process, to gradually develop a system of consultations and dialogue, cooperation and joint planning in conformity with the declared will to enhance regional interaction in meeting non-conventional and non-military challenges by sharing respective responsibilities. Bearing in mind that the institutionalisation of cooperation processes is crucial for the promotion of stability and security, the leaders of South East European states have launched a number of SEDM mechanisms and tools to address challenges and exploit opportunities.

Being an instrument for regional cooperation fostering stability, security and prosperity in South Eastern Europe and intending to streamline various security related efforts, the Stability Pact for South Eastern Europe provides tools for 
addressing most nontraditional challenges mentioned hitherto. It also supports state and institution building as well as social and economic consolidation within states of the region. It is a mechanism for focusing and channelling efforts and resources and by means of its working tables it develops a system of projects that target comprehensively security matters reinforcing the security network by "hardening" its soft dimension.

\section{The Tools}

Both the SEDM and the Stability Pact provide flexible frameworks within which various initiatives and projects are generated. For the reason of complementarity, a few of them have been selected to illustrate the extending and expanding networking of willing and able states in South Eastern Europe.

The Multinational Peace Force South Eastern Europe and its component, the SEEBRIG, gives countries a unique chance. It brings together units from NATO and Partnership for Peace countries that can be assigned to carry out peace support operations under UN or OSCE mandate based on the UN Charter. Following the combined joint task force (CJTF) principle, the Brigade's international composition allows for military from different countries with different background and tradition to work together on aligning practices and increasing interoperability, both in terms of techniques and attitudes. It constitutes a precedent in South Eastern Europe as smaller units come together under a joint command and staff and presents a challenge to both resolve and capabilities.

The Brigade became operational in May 2001 and its establishment has been accompanied by a number of staff and field exercises as well as computer-assisted ones. The intent to enhance the potential range of its activities in the future is related to a great extent to the South East European states' desire to produce security through regional sources and minimise the external support to regional stability. Ideas have also been voiced that the Brigade could be involved in missions in South Eastern Europe especially in the light of a possible US withdrawal from certain military engagements in this part of the world.

The fundamental notion of the Agreement on the establishment of the MPFSEE is that it is not aimed at allying against any country or group of countries. The decision to deploy the Multinational Brigade will be preceded by political and military consultations and will be subject to approval by participating states in conformity with their national legislation arrangements. Particular participation, tasks and rules of engagement as well as withdrawal from an operation will also be decided together though any country can withdraw its forces following due notification and consultations. $^{4}$ 
The Brigade's components come together for exercises and training. In such cases the MPFSEE headquarters, currently located in Plovdiv, is fully activated. It is also connected to the South East European Crisis Information Network (Concept sheet is provided in the appendix). In 1999 the SEDM also originated the Engineer Task Force within the MPFSEE to take part in rescue operations in the region and carry out small projects as an aid to Kosovo post-conflict reconstruction.

Another part of the network similar in concept to the MPFSEE though irrelevant to the SEDM process is the recently established Operational Group for Naval Cooperation in the Black Sea area (BLACKSEAFOR) bringing together countries selected by another regional criteria, willing to cooperate in search-and-rescue operations, humanitarian operations, mine-protection activities, environmental protection and other maritime operations. It comprises 4-6 ships from the Black Sea countries, including one for command and control.

The SEDM states have extended their cooperation to include other initiatives such as the SEESIM and SIMIHO. The South Eastern Europe Simulation Network (SEESIM) has been designed to facilitate SEDM countries in establishing integrated operational capabilities and reaching an average level of interoperability with NATO member states in terms of communications systems. It is a tool for integrating several related SEDM initiatives through a series of computer modelling and simulation-based exercises. The project for Satellite Interconnection of Military Hospitals (SIMIHO) is intended to cover a particular area of certain importance, with details regarding computer network, software, technical and communications equipment requirements still under discussion.

The SEDM was also the framework within which the Civil Military Emergency Planning Council (CMEP) was established to support and intensify regional cooperation, to study the possibilities for immediate effective planning and coordination of resources available for management of natural disasters, industrial accidents, etc.

A similar instrument exists within the Stability Pact for South Eastern Europe. The Disaster Preparedness and Prevention Initiative (DPPI) has been intended to promote regional cooperation and coordination in disaster prevention and preparedness, to reduce the impact of natural and technological disasters and to develop synergies and cooperation with existing or planned initiatives in the region with the close involvement of specialised agencies (UNDP, NATO, IFRC) and single countries (US, Italy, Sweden, Switzerland, etc.) without any excessive institutionalisation. $^{5}$

Based on a "Regional Assessment Report" drafted by a joint team led by Croatia and Bulgaria, an attempt to develop a regional strategy for disaster prevention, 
preparedness and response was put forward that, if implemented successfully, will require respective programmes and projects to sustain necessary resources and capabilities. It is facilitated by the initial identification of areas of action that include:

- information sharing and networking;

- "lessons learned" from disasters and exercises;

- standardisation and harmonisation;

- preparedness planning and exercises;

- cooperation in preparedness for seasonal and common risks, including joint contingency planning, preparedness exercises and measures and early warning systems;

- joint disaster management training with a special emphasis on technical, operational and other skills, exchange of plans, techniques and materials;

- public awareness and media relations;

- strengthening local structures and involving communities in the DPPI dialogue;

- $\quad$ border crossing procedures. ${ }^{6}$

These areas of action are referred to by means of certain mechanisms that include information/expertise exchange, working groups, joint reports, exercises, conferences and seminars, establishing data base of focal points, 24-hour contacts in national emergency centres and international organisations; communicating reports and information on national organisations and structures, and on emergency management procedures. Progress has been made on the consolidation of the Disaster Management Training (DMT) Programme for South Eastern Europe as well as particular projects, such as the Joint Fire Fighting Unit Croatia/Bosnia and Herzegovina/the Federal Republic of Yugoslavia - Montenegro, etc.

The Stability Pact has been the background for a number of other initiatives as well. The Anti-Corruption Initiative (SPAI) is intended to give a decisive impetus to the fight against corruption in the region through a comprehensive set of actions under five pillars:

- adoption and implementation of European and other international instruments;

- $\quad$ promotion of good governance and reliable public administrations;

- strengthening of legislation and promotion of the rule of law;

- promotion of transparency and integrity in business operations;

- $\quad$ promotion of an active civil society ${ }^{7}$. 
As organised crime has been considered as one of the gravest problems in South Eastern Europe with specific political, economic, social and psychological implications and references, related to the region's geographic location and historic legacy, an Initiative to Fighting Organised Crime (SPOC) ${ }^{8}$ has been launched to help South East European states counter actions of criminal groupings that are often irregularly structured and transnationally supported. Weak institutions, failure of coordination, and insufficient resources to withstand make the organised crime a threat to fragile democracies in the region. Thus SPOC is a tool that helps identify problems and objectives and mobilise regional and international resources to achieve these objectives, provide targeted assistance for policies, institutions and capacities and ensure political commitment.

The fight against organised crime is a national effort that by means of SPOC is placed within the institutional and legal framework of the UN, the OSCE, the EU, the Council of Europe, and assisted by the expertise of other institutions such as Europol, Interpol, the Southeastern Europe Cooperation Initiative (SECI), the Central European Initiative (CEI), and the Adriatic Sea Initiative.

The objectives of SPAI and SPOC have been supported by the Council of Europe's Programme against Corruption and Organised Crime in SEE (PACO) that targets policies, effectiveness of justice and regional cooperation. Recently a special project aimed at strengthening networking among countries of the region through direct communications among judicial authorities, similar to the European Judicial Network, has been launched. Further efforts in this area will be very much influenced by the recent developments in the EU where most of the South East European countries aspire. The extended internal exchange and cooperation and the establishment of a common border police and rules for fighting money laundering and terrorism will affect the aspirants as well in their efforts to meet the requirements under the Union's third pillar especially regarding the EU policy standards and practices pursued in the reform of law enforcement institutions.

There are other channels that contribute to that end too. By exchange of knowledge and experience the Stability Pact's Regional Police Training Initiative aims at bringing forward best regional and international practices and developing a network for cooperation. It will be institutionalised through the Southeast European Police College that is supported by the Association of European Police Colleges (AEPC), the Central European Police Academy and the Nordic Baltic Police Academy and intended to enhance police skills, democratic policing, and develop regional networks and cooperation in joint fight against transnational organised crime.

Organised crime, illegal trafficking and terrorism are also items on the agenda of another regional arrangement, the Southeast European Cooperative Initiative 
$(S E C I){ }^{9}$ It is a flexible framework that addresses as well issues like good-neighbourly relations, economic cooperation, infrastructure development, humanitarian, social and cultural contacts. In compliance with the Agreement on cooperation to prevent and combat trans-border crime, ${ }^{10}$ the South East European states have agreed to cooperate by providing assistance in the form of information or expertise exchange. A special SECI Regional Centre for Combating Trans-border Crime ${ }^{11}$ has been established in Romania to help develop effective joint interagency working relations.

There are other examples that can also be cited to illustrate the dynamic networking in South Eastern Europe like the Migration and Asylum Initiative or the Border Control Initiative, ${ }^{12}$ the forum of East European intelligence and counterintelligence services, established in May 2002 in Romania, the so called 2+2 initiative involving Bulgaria, Greece, Romania and Turkey and supporting the candidates' aspiration to join NATO but intended to evolve beyond and cover other issues as well, etc. All these tools, designed to manage cooperatively, or support national efforts regarding, regional challenges, have some common features though the kind of response and scope of commitment varies respectively.

The management of non-traditional challenges is a process that relies extensively on exact and timely information for any decision-making at any stage: planning, organisation, implementation or assessment/control. All of the initiatives mentioned above can only be possible if information is exchanged and it is exchanged properly. Therefore, the development of an adequate and effective information environment to support any management attempt is essential. This understanding has facilitated the ever-growing use of computer systems and IT on national and international scales. It also encouraged the introduction and spread of the Partnership for Peace Information Management System (PIMS) ${ }^{13}$ that is a flexible tool for ensuring efficient and reliable capabilities and information exchange among states and organisations by means of IT and common infrastructure. It is intended to enhance regional cooperation, facilitate communications, workshops, conferences, exercises and daily operations. It is a venue for collaborative information sharing, but also for interoperability enhancement. The PIMS network is enjoyed by state institutions in many countries, incl. ministries of defence, ministries of foreign affairs, civil protection organisations, law enforcement bodies, etc. It is also a secure domain for SEDM and CMEP planning and emergency management.

Since 1999 the PIMS web has been enhanced by the SEDM's Crisis Information Network $(C I N)^{14}$ that, among others, is intended to expand the reach of PIMS to meet new crisis management requirements by ensuring fast information exchange, interoperability and coordination of national activities in disasters and crises as well as support to $\mathrm{C} 2$ systems. It will be further enhanced by the prospective activation of 
the Global Disaster Information Network (GDIN) as a means of exchanging CMEPrelated information. ${ }^{15}$

The mechanisms, tools and arrangements described above come to confirm the resolve of countries in the region to sustain communities and networks "for" and not "against", in an environment that is extremely dynamic in development and abundant in opportunities. The diversity of this security environment demands the evolution of capabilities and structures of national security organisations in order to successfully address current and possible future challenges. It is much about changes of concept and mind but it is also about developing certain skills and attitudes that can interact cohesively within the national and international environment and support effectively political strategies. It is also about consistency of philosophy and flexibility of approach that South East European countries have started to gradually adopt in meeting together common security challenges, thus making way for a stable, prosperous and secure future for all. 
Annex

\section{CRISIS INFORMATION NETWORK CONCEPT OF OPERATION}

\section{Scope}

The multinational Crisis Information Network (CIN) is to provide SEDM nations with an information technology support to help coordinate regional civil-military assistance and emergency relief projects. Initially, this will be a PIMS-based capability primarily oriented toward support of the Engineer Task Force. In the longer term, the initiative could be oriented towards improving interoperability between existing national information systems. In the future, the initial CIN capability might be used to develop a mechanism for coordinating assistance and intervention from all sources in regional emergencies and civil-military assistance situations.

\section{Mission}

The Crisis Information Network (CIN) mission is to provide the participating nations with a reliable, low cost, high technology, interoperable, standards-based communication and information exchange environment to be used for crisis management, coordination of emergency relief and regional civil-military assistance.

\section{Functions}

The SEDM nations have agreed that in the near term:

A. The Partnership for Peace Information Management System (PIMS) will serve as the initial phase CIN, alone or in conjunction with national systems.

B. PIMS will provide an initial database and planning capability focused on supporting the SEDM Engineer Task Force (ETF) and Civil-Military Emergency Planning (CMEP) initiatives.

C. A mapping capability should be added (this will require additional PIMS support).

\section{Command and Control, Organisation}

In order to implement the initiative as quickly as possible, the following step-by-step approach is proposed:

A. Phase I

(1) Identify users, locations, and types of information to be exchanged in support of small-scale bilateral or multilateral projects to be conducted under the auspices of the ETF. 
(2) Initial PIMS connectivity is required for SEEBRIG, PMSC*, and other non-governmental organisations associated with ETF and CMEP tasks.

(3) The CIN Working Group will form a subgroup devoted exclusively to monitoring the effectiveness of information technology support for the ETF "customer support" needs in each SEDM nation.

B. Phase II

(1) As the PIMS-based CIN matures in its support of the ETF, nations will examine a wider $\mathrm{C} 2$ architecture to permit wider coordination, on the following options:

(a) CIN coordinated under the authority of the PMSC.

(b) "Stand alone" CIN with some suitable political-military direction.

(2) Because alternative approaches may imply different multinational system support integration requirements, the CIN Working Group will establish a second subgroup. This subgroup will exist solely to permit a multinational consultation process for:

(a) Improving the interoperability between the separate national Crisis Information Systems.

(b) Considering the development of a mechanism for coordinating assistance and contributions from all sources, in regional emergencies and civil-military assistance situations.

(c) Coordinating the development of a civilian and military council for planning regional cooperation in response to disasters. The schedule of workshops led by Civil Protection organisations of the SEDM nations will be adapted for mutual support with the long-term development of CIN.

\section{CIN System Availability and Composition}

Contributing nations determine their level of participation in providing technical support to CIN.

The United States provides the PIMS capability to support initial connectivity required to support implementation of ETF and CMEP activities. If necessary in the future, augmentation of CIN to higher levels of capability beyond PIMS will be at the expense of the participating nations.

The United States agrees to help facilitate discussions among nations in order to coordinate effective multinational collaboration that may result in an enhanced CIN capability above that provided by PIMS.

* Political Military Steering Committee 


\section{Notes:}

1 Report of the First Committee-(A/55/552, 20 December 2000). Resolution adopted by the UN General Assembly <http://daccess-ods.un.org/doc/UNDOC/GEN/N00/561/01/ PDF/N0056101.pdf?OpenElement> (6 October 2002).

2 South East Europe Common Assessment Paper on Regional Security Challenges and Opportunities (SEECAP), (Budapest, Hungary adopted May 2001), <http://www.nato.int/docu/comm/2001/0105-bdp/d010530b.html> (12 May 2002).

3 Ibid.

$4 \quad$ Agreement on the Multinational Peace Force South Eastern Europe, signed September 1998 by SEDM states.

5 Disaster Preparedness and Prevention Initiative (DPPI), Strategy and Next Steps, (Regional conference, Bucharest, 25 and 26 October, 2001).

6 Ibid.

7 SPAI Strategy and Action Plan for 2002 and beyond, (Formally endorsed at the Budapest Working Table II meeting of the Stability Pact in November 2001), available online at http://www1.oecd.org/daf/SPAIcom/Word/strategy.doc

8 Stability Pact. Fight against Organised Crime, (Regional conference, Bucharest, 25 and 26 October, 2001).

9 See http://www.unece.org/seci/.

10 SECI Agreement on Cooperation to Prevent and Combat Trans-border Crime, available at http://www.unece.org/seci/crime/agreemnt.htm.

11 Charter of the Organisation and Operation of the Southeast European Initiative Regional Centre (SECI Centre) for the Combating of Trans-border Crime, <http://www.unece.org/ seci/crime/charter.htm> (12 April 2002).

12 For more information see http://www.stabilitypact.org.

13 http://www.pims.org.

14 In May 1999, at a meeting of the deputy-ministers of defence of SEDM countries Bulgaria put forward a proposal to create a Crisis Information Network. A Concept of Operation of the Network was approved by the ministers of defence of SEDM countries during their meeting in Bucharest, Romania, in December 1999.

15 Charles R. Myer, "C4ISR Architectural Frameworks in Coalition Environments," in Information \& Security 5, (2000): 60-72, <http://www.isn.ethz.ch/onlinepubli/ publihouse/infosecurity/volume_5/a3/a3_index.htm> (12 April 2002).

PETYA DIMITROVA was born in 1975 in Sofia. She holds a Master degree in International Relations from the Faculty of Law of St. Kliment Ohridski Sofia University. She is a senior expert at the Defence Policy department of the Defence Policy and Planning Directorate of the Bulgarian Ministry of Defence. Her area of interest covers issues like European security dimensions, decision-making and strategy implementation, management, etc.

E-mail:bruja17@yahoo.com. 